\title{
Measures of Bone Mineral Content in Mature Dairy Cows
}

\author{
B. E. Keene ${ }^{1, \star}{ }^{\star}$ K. F. Knowlton, ${ }^{1}$ M. L. McGilliard, ${ }^{1}$ L. A. Lawrence, ${ }^{2,} \dagger$ \\ S. M. Nickols-Richardson, ${ }^{3}$ J. H. Wilson, ${ }^{4}$ A. M. Rutledge, ${ }^{1}$ \\ L. R. McDowell, ${ }^{5}$ and M. E. Van Amburgh ${ }^{6}$ \\ ${ }^{1}$ Department of Dairy Science, \\ ${ }^{2}$ Department of Animal and Poultry Sciences, \\ ${ }^{3}$ Department of Human Nutrition, Foods and Exercise, and \\ ${ }^{4}$ Department of Biological Systems Engineering, \\ Virginia Polytechnic Institute and State University, Blacksburg 24061 \\ ${ }^{5}$ Department of Animal Sciences, University of Florida, Gainesville 32611 \\ ${ }^{6}$ Department of Animal Science, Cornell University, Ithaca, NY 14853
}

\section{ABSTRACT}

The objectives of this investigation were to assess the relationship between chemical measures and imaging estimates (radiographic photometry and dual-energy xray absorptiometry) of bone mineral content in dairy cows and to evaluate the effects of parity, stage of lactation, and site of measurement (fused third and fourth metacarpal bone vs. caudal vertebrae 14 and 15) on bone mineral content. In a preliminary study, the caudal vertebrae were excised from 33 cows following slaughter. Samples were analyzed by radiographic photometry and then analyzed for mineral content chemically. In a second experiment, the caudal vertebrae and right front metacarpal (sample pairs) were excised from 107 Holstein cull cows following slaughter. Parity and days in milk (DIM) of the donor animals were obtained for 43 pairs of samples. Samples were grouped by parity $(1,2,3$, and $\geq 4)$ stage of lactation (Stage 1: $<90$ DIM, Stage 2: 90 to 150 DIM, Stage 3: 151 to 250 DIM, and Stage 4: >250 DIM). Samples were analyzed by radiographic photometry and dual-energy x-ray absorptiometry and then analyzed for mineral content chemically. In both experiments, the relationship between mineral content estimated via the imaging techniques and mineral content measured chemically was poor, likely because of the relative maturity of animals in the sample set and lack of variation in mineral content. Ash content was higher in the metacarpal than in the caudal vertebrae, as were concentrations of $\mathrm{Mg}$ (expressed as a proportion of bone ash). No effects of stage of lactation were observed on bone mineral in the caudal

Received April 1, 2004.

Accepted June 22, 2004.

Corresponding author: K. F. Knowlton; e-mail: Knowlton@vt.edu.

*Current address: Department of Agriculture and Natural Resources, Morrisville State College, Morrisville, NY.

$\dagger$ Current address: Kentucky Equine Research, Versailles, KY 40383. vertebrae, but in the metacarpal, $\mathrm{P}$ content (proportion of total mineral) was highest in second lactation cows. Total bone mineral content (ash) was not affected by parity in the metacarpal or caudal vertebra, but $\mathrm{Ca}$ and $\mathrm{P}$ content of the metacarpal increased with parity. Noninvasive imaging techniques are not sufficiently sensitive to detect changes in mineral content or composition of mature cows, and only modest changes in bone mineral were observed with stage of lactation and parity.

(Key words: bone mineral content, radiographic photometry, dual-energy x-ray absorptiometry)

Abbreviation key: BMC = bone mineral content, BMD = bone mineral density, DXA = dual-energy x-ray absorptiometry, RBAE = radiographic bone aluminum equivalents, $\mathbf{R P}=$ radiographic photometry.

\section{INTRODUCTION}

Bone is a dynamic tissue that performs mechanical, biological, and chemical functions. Bone development and chemical and physical properties of bone are affected by age, nutrition, hormonal status, and disease (Loveridge, 1999). The skeletal system forms the external structure and appearance of mammalian vertebrate species and has the obvious functions of locomotion, structural support of the body, and protection of soft tissue (brain, heart, spinal cord, and lungs). Bone also serves as a metabolic reservoir for $\mathrm{Ca}, \mathrm{P}$, and other minerals, and it houses cells responsible for bone formation and resorption. Bone remodeling provides $\mathrm{Ca}$ to meet the demands of eggshell formation in poultry (Dacke et al., 1993) and milk synthesis in lactating dairy cows (Horst et al., 1997).

All bone consists of mineral, primarily hydroxyapatite $\left(\mathrm{Ca}_{10}\left(\mathrm{PO}_{4}\right)_{6}(\mathrm{OH})_{2}\right)$ deposited in an organic matrix, of which collagen is the major constituent. Bone mineral is deposited in large numbers of small crystals, giving 
bone a large surface area. The surface area of $1 \mathrm{~g}$ of bone mineral is estimated to be $>100 \mathrm{~m}^{2}$ (Omnell, 1957); this surface area allows for a rapid interchange of ions between interstitial fluid and bone.

Bone mineral content (BMC) is a result of the balance between bone formation and resorption, and it is influenced by diet, age, and physiological state. In adult mammals, approximately $20 \%$ of the bone wet weight is water, $45 \%$ is ash, and $35 \%$ is OM (Carter and Spengler, 1978). Calcium contributes $37 \%$ of the ash content, and $\mathrm{P}$ contributes $18.5 \%$. On a dry weight basis, mineral content is 65 to $70 \%$, and $\mathrm{OM}$ is 30 to $35 \%$. Bone loss occurs when resorption exceeds bone formation, with osteoporosis in humans as a classic example of bone imbalance in part attributable to diet. This chronic condition results in fractures and loss of bone mass.

In ruminants, changes in BMC have been reported or inferred during lactation (Benzie et al., 1959; Braithwaite, 1983; Knowlton and Herbein, 2002) and with diet. Shupe et al. (1988) reported signs of osteoporosis in beef cattle fed low amounts of $\mathrm{P}$ ( 6 to $12 \mathrm{~g} / \mathrm{d})$ for $2 \mathrm{yr}$.

Bone $\mathrm{P}$ content has been used as an indicator of $\mathrm{P}$ deficiency in lactating cows (Wu et al., 2001), and such an indicator would be useful in the field. The link between overfeeding $\mathrm{P}$ and increased $\mathrm{P}$ excretion is well established (Morse et al., 1992; Wu et al., 2000; Knowlton and Herbein, 2002), but the variability in P content of feeds and its uncertain bioavailability creates risk associated with underfeeding (impaired growth or milk yield). An on-farm, noninvasive tool to assess the $\mathrm{P}$ status of cows would allow dairy producers and their advisors to revise dietary $\mathrm{P}$ to reduce the overfeeding common in the field (Sink et al., 2000). Direct chemical assessment of BMC requires either bone biopsy (Little, 1972), surgical removal of bone sections (Wu et al., 2001 ), or postmortem assessment, none of which is practical in a production setting.

In addition to their use as a tool to allow refined diet formulation, noninvasive measures would also be useful to monitor changes in BMC during lactation. Two imaging techniques, dual-energy $\mathrm{x}$-ray absorptiometry (DXA) and radiographic photometry (RP), have been used as noninvasive predictors of BMC in other species.

The DXA method assesses BMC, bone mineral density (BMD), and bone area with low radiation (Mazess et al., 1990; Adams, 1997) and low precision error $(<1 \%$; Mazess et al., 1990). The method is used extensively in human bone research, and it is considered the "gold standard" method to assess the potential for bone fractures in humans (Mazess et al., 1990). Some research has been conducted with DXA in swine (Mitchell et al., 1996; Yang et al., 1998; Mitchell et al., 2001) and chickens (Mitchell et al., 1997), but its use in livestock is limited because of its high cost and low weight limit (136 kg).

Radiographic photometry has been used to estimate BMC and evaluate the effect of nutrition and condition on BMC in horses (Meakim et al., 1981; Porr et al., 1998; Hoffman et al., 1999) and beef cattle (Williams et al., 1991). Radiographic photometry utilizes a portable x-ray unit, x-ray film, scanning equipment, and imaging software to estimate BMC. X-rays are absorbed by $\mathrm{Al}$ to the same degree as bone mineral (Ekman et al., 1970), allowing use of an $\mathrm{Al}$ step wedge as a reference standard. The BMC estimated via RP is expressed in radiographic bone aluminum equivalents (RBAE) in millimeters of $\mathrm{Al}$. There are no published reports of the use of DXA or RP to estimate BMC in dairy cattle.

The objectives of the study were to evaluate RP and DXA as predictors of BMC in mature dairy cows and to evaluate the effects of parity, stage of lactation, and site of measurement (fused third and fourth metacarpal bone vs. caudal vertebrae 14 and 15) on BMC.

\section{MATERIALS and METHODS}

\section{Sample Collection}

Experiment 1. Caudal vertebrae from cows $(\mathrm{n}=33)$ were excised and collected at slaughter (Taylor Packing, Wyalusing, PA) and stored frozen. No information was available on breed, age, or physiological status of donor animals.

Experiment 2. Caudal vertebrae and right front metacarpals (sample pairs) from Holstein cows ( $\mathrm{n}=$ 107) were excised and collected at slaughter (Taylor Packing) and stored frozen. Information on parity, age, and DIM was obtained for donor animals for 43 sample pairs. Within this subset, sample pairs were grouped by DIM and parity to allow evaluation of the effects of these factors.

\section{Sample Analysis}

$\boldsymbol{R P}$ (Experiments 1 and 2). Dorsopalmer and anterior-posterior radiographs were taken of caudal vertebrae 14 and 15 using a high frequency portable x-ray unit (MinXRay HF-80; MinXRay, Northbrook, IL). Radiographs of caudal vertebrae (experiments 1 and 2) were taken ( $75 \mathrm{KV}, 0.04 \mathrm{~s}, 66-\mathrm{cm}$ focal distance) on Kodak TMGRA radiographic film in a Kodak Lenex regular screen $(18 \times 43 \mathrm{~cm})$. Radiographs of the metacarpal (experiment 2 only) were taken $(80 \mathrm{KV}, 0.06 \mathrm{~s}$, 66-cm focal distance) on Kodak TMGRA radiographic film in a Kodak Lenex regular screen $(24 \times 30 \mathrm{~cm})$. For all radiographs, an 11-step $\mathrm{Al}$ step wedge was taped to each screen and exposed simultaneously in each radiograph as a reference standard. Film was developed us- 
ing an automatic processor (Kodak RP X-Omat; model M-6).

X-ray images were scanned (Epson Expression 1680 scanner) and transferred to imaging software (ImagePro Plus for Windows, version 4.5, Media Cybernetics, Silver Springs, MD). For each film, a calibration curve was developed using the 11-step standard $\mathrm{Al}$ step wedge. In the metacarpal, a location $10 \mathrm{~cm}$ from the nutrient foramen was evaluated. Observations of RBAE recorded were as follows: 1) peak medial RBAE, mm $\mathrm{Al}$, which is the point of highest absorbance (greatest mineralization) on the medial side of the bone; 2) peak lateral $\mathrm{RBAE}, \mathrm{mm} \mathrm{Al}$, which is the point of highest absorbance on the lateral side of the bone; 3 ) bone width, $\mathrm{mm}$, which is the width of the widest part of the bone; 4) cortical width, $\mathrm{mm}$, which is the width of bone less the width of the medullary cavity; 5) bone length, mm, which is the total length of bone (caudal vertebrae only).

DXA (Experiment 2 only). Samples were thawed, and $\mathrm{BMC}$ and $\mathrm{BMD}$ were measured on each metacarpal and caudal vertebrae 14 and 15 using DXA (QDR 4500 A; Hologic, Inc., Bedford, MA) with the standard lumbar spine (L1-L4) and forearm protocols (Beiseigel and Nickols-Richardson, 2002). Caudal vertebrae and metacarpals were placed prone on the table, and anteriorposterior scans were performed. Both BMD $\left(\mathrm{g} / \mathrm{cm}^{2}\right)$ and $\mathrm{BMC}(\mathrm{g})$ were estimated for caudal vertebrae 14 and 15 and the metacarpal.

BMC (Experiment 1). Bone samples were dried in an oven at $105^{\circ} \mathrm{C}$ for $16 \mathrm{~h}$, and fat was removed by petroleum-ether extraction. The bones were again dried at $105^{\circ} \mathrm{C}$ overnight, weighed, and ashed in a muffle furnace at $600^{\circ} \mathrm{C}$ overnight. Ash weight was recorded. Ash was solubilized in $\mathrm{HCl}$ (Miles et al., 2001), samples were analyzed for $\mathrm{Ca}$ and $\mathrm{Mg}$ by flame atomic absorption spectrophotometry (Perkin-Elmer 5000; Perkin-Elmer Corp., Norwalk, CT), and P was determined colorimetrically (Harris and Popat, 1954). Macro-elements were expressed as a percentage of ash on a dry, fatfree basis.

BMC (Experiment 2). After imaging analysis was completed, mechanical tests of breaking strength were conducted (Keene et al., 2004), and a band saw was used to cut the metacarpal into $1-\mathrm{cm}$ cross sections $( \pm 0.01 \mathrm{~mm})$ on either side of a mark, indicating the point $10 \mathrm{~cm}$ from the nutrient foramen. The caudal vertebrae (complete bones) and metacarpal $(2 \mathrm{~cm} \mathrm{sec-}$ tions) were analyzed for total mineral content by ashing the bone. Samples were dried to a constant weight at $105^{\circ} \mathrm{C}$ and then ashed in a muffle furnace at $600^{\circ} \mathrm{C}$ for $12 \mathrm{~h}$ (AOAC, 1990). Concentrations of $\mathrm{Ca}, \mathrm{P}$, and $\mathrm{Mg}$ were assessed via inductively coupled plasma and expressed as a proportion of bone ash.

\section{Statistical Analyses}

Experiment 1. Thirty-three caudal vertebrae samples were used to analyze the relationship between RP and chemical measures of BMC. Regression analysis was conducted using the simple regression model in PROC REG in SAS version 8.0 (SAS Institute, 1999).

$$
\mathrm{Y}_{\mathrm{i}}=\beta_{0}+\beta_{1} \mathrm{X}_{\mathrm{ij}}+\mathrm{e}_{\mathrm{ij}}
$$

where

$\mathrm{Y}_{\mathrm{i}}=$ response for the dependent variable (all $\mathrm{RP}$ measures),

$\mathrm{X}_{\mathrm{ij}}=$ independent variable (all chemical measures of $\mathrm{BMC}$ ),

$\beta_{0}=$ intercept estimate,

$\beta_{1}=$ slope estimate (regression of $\mathrm{RP}$ measures on chemical measures of BMC), and

$\mathrm{e}_{\mathrm{ij}}=$ residual error.

For all statistical analyses, effects were declared significant at $P<0.05$ and trends at $P<0.10$.

Experiment 2: Relationship between imaging and chemical measures of BMC. Seventy-eight pairs of caudal vertebrae and metacarpals were used to calculate the relationship between chemical and imaging (RP and DXA) measures of BMC. The sample set was incomplete because 29 of the 107 original metacarpal samples were collected in a way that prevented identification of a reference point $10 \mathrm{~cm}$ from the nutrient foramen, an important landmark. Regression analysis was conducted using the simple regression model in PROC REG in SAS version 8.0 (SAS Institute, 1999).

$$
\mathrm{Y}_{\mathrm{i}}=\beta_{0}+\beta_{1} \mathrm{X}_{\mathrm{ij}}+\mathrm{e}_{\mathrm{ij}}
$$

where

$$
\begin{aligned}
\mathrm{Y}_{\mathrm{i}}= & \text { response for the dependent variable (all RP and } \\
& \text { DXA measures), } \\
\mathrm{X}_{\mathrm{ij}}= & \text { independent variable (all chemical measures of } \\
& \text { BMC), } \\
\beta_{0}= & \text { intercept estimate, } \\
\beta_{1}= & \text { slope estimate (regression of } \mathrm{RP} \text { and DXA mea- } \\
& \text { sures on chemical measures of BMC), and } \\
\mathrm{e}_{\mathrm{ij}}= & \text { residual error. }
\end{aligned}
$$

Experiment 2: Relationship of BMC with site of measurement. Seventy-eight pairs of caudal vertebrae and metacarpals were used to evaluate the relationship with the site of measurement on BMC. Data were analyzed using PROC Mixed in SAS version 8.0 (SAS Institute, 1999) with the following model: 


$$
\mathrm{Y}_{\mathrm{ij}}=\mu+\mathrm{a}_{\mathrm{i}}+\mathrm{b}_{\mathrm{j}}+\mathrm{e}_{\mathrm{ij}}
$$

where

$$
\begin{aligned}
\mathrm{Y}_{\mathrm{ij}}= & \text { response of dependent variable (chemical mea- } \\
& \text { sures of } \mathrm{BMC}), \\
\beta= & \text { mean } \\
\mathrm{a}_{\mathrm{i}}= & \text { fixed effect of site (metacarpal, caudal vertebrae } \\
& 14 \text { and } 15), \\
\mathrm{b}_{\mathrm{j}}= & \text { random effect of cow, and } \\
\mathrm{e}_{\mathrm{ij}}= & \text { residual error. }
\end{aligned}
$$

Using preplanned contrasts, values for the metacarpal were compared with values for the caudal vertebrae, and values for caudal vertebra 14 were compared with values for caudal vertebra 15. Results are presented as least squares means.

Experiment 2: Relationship of BMC with stage of lactation. Forty-three sample pairs of caudal vertebrae and metacarpals (all samples for which stage of lactation was available) were used to evaluate the effects of stage of lactation on BMC. Sample sets were grouped by stage of lactation (Stage 1: $<90$ DIM, Stage 2: 90 to 150 DIM, Stage 3: 151 to 250 DIM, Stage 4: $>250$ DIM). The relationship of chemical measures of BMC with stage of lactation was analyzed using Proc GLM of SAS version 8.0 (SAS Institute, 1999) with the following model:

$$
\mathrm{Y}_{\mathrm{i}}=\mu+\mathrm{a}_{\mathrm{i}}+\mathrm{e}_{\mathrm{ij}}
$$

where

$$
\begin{aligned}
Y_{i} & =\text { response (chemical measures of BMC), } \\
\mu & =\text { mean, } \\
a_{i} & =\text { fixed effect of stage of lactation }(i=1 \text { to } 4), \text { and } \\
e_{i j} & =\text { residual error. }
\end{aligned}
$$

Experiment 2: Relationship of BMC with parity. Forty-three sample pairs of caudal vertebrae and metacarpals (all samples for which parity was available) were used to evaluate the effects of parity on BMC. Sample sets were grouped by parity $(1,2,3,4)$. The relationship of parity with $\mathrm{BMC}$ was analyzed using Proc GLM of SAS version 8.0 (SAS Institute, 1999) with the following model:

$$
\mathrm{Y}_{\mathrm{i}}=\mu+\mathrm{a}_{\mathrm{i}}+\mathrm{e}_{\mathrm{ij}}
$$

where

$$
\begin{aligned}
\mathrm{Y}_{\mathrm{i}} & =\text { response (chemical measures of } \mathrm{BMC}), \\
\mu & =\text { mean, }
\end{aligned}
$$

a

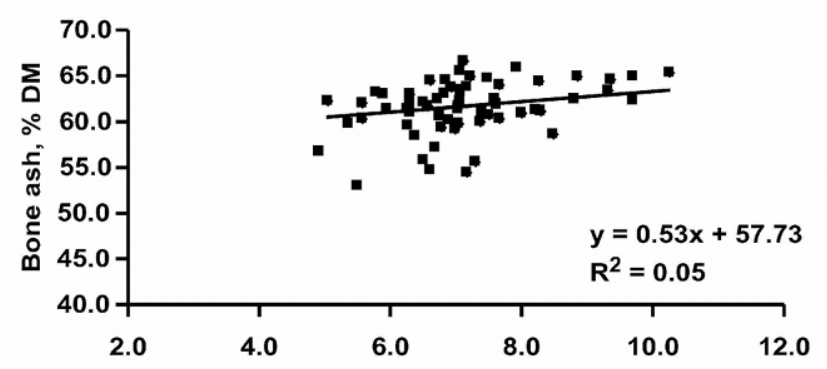

b

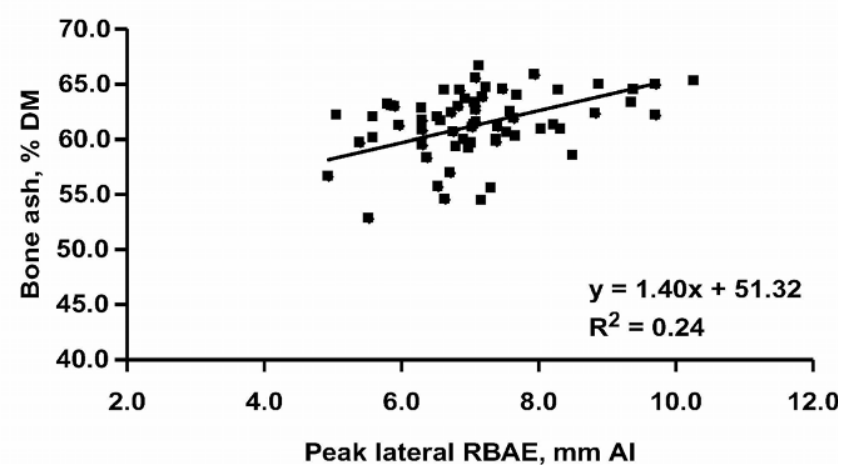

Figure 1. Relationship between bone ash and radiographic bone aluminum equivalents (RBAE) in caudal vertebra 14 (a) and vertebra 15 (b) of 33 cows (experiment 1 ).

$a_{i}=$ fixed effect of parity ( $\mathrm{i}=1$ to 4 lactations), and $\mathrm{e}_{\mathrm{ij}}=$ residual error.

It would have been preferable to include stage of lactation and parity in the same model, but the number of cows within each subclass was small. Linear and quadratic effects of stage of lactation and parity were assessed using preplanned contrasts. Linear, quadratic, and cubic regressions of BMC and breaking strength on DIM were fit, but the data were unequally distributed, and effects were not significant (results not shown). Data are presented as least square means.

\section{RESULTS AND DISCUSSION}

\section{Relationships Between Measures of BMC in Dairy Cows}

Chemical and RP measures. Weak relationships were observed between chemical and RP measures of $\mathrm{BMC}$ in caudal vertebrae 14 and 15 in experiment 1 (Figures 1, a and b) and in caudal vertebrae 14 and 15 and the metacarpal in experiment 2 (Table 1). In experiment 1 , the relationship was stronger in the larger caudal vertebra 15 than in caudal vertebra 14 . Radiographic bone $\mathrm{Al}$ equivalents accounted for $24 \%$ of the variation in bone ash in the former but only $5 \%$ in 
Table 1. Relationship between radiographic photometric and chemical measures of bone mineral content in mature dairy cows.

\begin{tabular}{|c|c|c|c|c|}
\hline & $\mathrm{Ca}, \%$ of ash & $\mathrm{P}, \%$ of ash & $\mathrm{Mg}, \%$ of ash & Ash, $\%$ of DM \\
\hline & 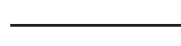 & Coefficient of & rmination $\left(\mathrm{r}^{2}, \mathrm{q}\right.$ & \\
\hline \multicolumn{5}{|l|}{ Caudal vertebra 14} \\
\hline Peak medial $\mathrm{RBAE},{ }^{1} \mathrm{~mm} \mathrm{Al}$ & 0.9 & 1.4 & 1.5 & $3.5 \dagger$ \\
\hline Peak lateral RBAE, mm Al & 0.3 & 0.5 & 0.6 & $6.8^{*}$ \\
\hline Bone length, mm & 0.2 & 0.6 & 0.4 & $3.0 \dagger$ \\
\hline Bone width, mm & 0.1 & 0.4 & 0.3 & 1.4 \\
\hline Cortical width, mm & 0.1 & 0.1 & 0.0 & 1.8 \\
\hline \multicolumn{5}{|l|}{ Caudal vertebra 15} \\
\hline Peak medial RBAE, mm Al & 0.2 & 2.0 & 1.8 & 2.0 \\
\hline Peak lateral RBAE, mm Al & 0.4 & 0.2 & 2.3 & 1.1 \\
\hline Bone length, mm & 0.1 & 0.7 & 0.8 & 0.4 \\
\hline Bone width, mm & 0.1 & 0.8 & 0.4 & 0.5 \\
\hline Cortical width, mm & 0.0 & 1.3 & 0.4 & $3.0 \dagger$ \\
\hline \multicolumn{5}{|l|}{ Metacarpal } \\
\hline Peak medial RBAE, mm Al & $5.1^{*}$ & $4.4^{*}$ & $3.9 \dagger$ & 0.3 \\
\hline Peak lateral RBAE, mm Al & $6.2^{*}$ & $5.4^{*}$ & $5.4 \dagger$ & 1.0 \\
\hline Bone width, mm & $6.3^{*}$ & $5.5^{*}$ & $5.1^{*}$ & 0.1 \\
\hline Cortical width, mm & $6.1^{*}$ & $5.5^{*}$ & $6.1^{*}$ & 1.7 \\
\hline
\end{tabular}

${ }^{1} \mathrm{RBAE}=$ Radiographic bone $\mathrm{Al}$ equivalents.

*Regression significant at $P<0.05$.

$\dagger$ Regression significant at $P<0.10$.

the latter. The reason for the much stronger relationship between RBAE and bone ash in the caudal vertebra 15 is unclear. Total bone ash tended to be higher in the smaller caudal vertebra 14 , but differences were small (61.6 vs. $61.0 \% ; P<0.10)$.

In experiment 2 , coefficients of determination between RBAE and most mineral measures were $<5 \%$. In the strongest relationship, peak lateral RBAE accounted for $6.8 \%$ of the variation in measured total bone ash (caudal vertebra 14; Table 1). Although no relationship was large, it appears that in the caudal vertebrae, RP measures reflected total bone ash, whereas in the metacarpal, $\mathrm{RP}$ was more predictive of the individual minerals $(\mathrm{Ca}, \mathrm{P}$, and $\mathrm{Mg}$ ) than of total BMC.

The observations in the current study fail to reflect the strong predictive relationship between RBAE estimates and chemical measures of BMC observed in the metacarpal of horses (Meakim et al., 1981; Lawrence, 1986; Hoffman et al., 1999) and beef cattle (Williams et al., 1990). In these studies, coefficients of determination of $>90 \%$ were observed. One possible explanation for this contradiction is the relative maturity of the sample donors in the current studies. In studies reporting strong relationships between BMC measured chemically and estimated via RP, the experimental units were growing animals (Meakim et al., 1981; Lawrence, 1986; Hoffman et al., 1999) with a wide range of observed BMC. In the current experiments, samples were collected from mature cows at slaughter. No data were obtained on the age of the donor animals in experi- ment 1 , but, in experiment 2 , the 43 cows for which age information was available ranged in age from 3 to $6 \mathrm{yr}$. Radiographic photometry may not be sensitive enough to detect small differences in BMC in mature animals.

The relationships between chemical and RP measures of BMC were somewhat stronger in experiment 1 than in experiment 2 . The relationship between bone ash and peak lateral RBAE was significant in the CV 15 of the 33 samples in experiment 1, with RBAE accounting for more variation in bone ash than in any bone in experiment 2 . The difference may be due to differences in methods of assessing bone ash in the 2 studies. In experiment 1 , bone ash was expressed as a proportion of the fat-free DM, whereas fat was not extracted from samples prior to mineral analysis in experiment 2. Even within experiment 1, however, the coefficient of determination was much lower than was observed in the studies focusing on growing beef cattle or horses (Meakim et al., 1981; Lawrence 1986; Hoffman et al., 1999).

Chemical and DXA measures (experiment 2). Although the weight limit and expense of the equipment prevents its use as a field tool for assessing mineral status, DXA was evaluated in the current study because of its status as the primary means of assessing body content in humans and for its potential as a research tool. As with RP, however, only weak relationships were observed between chemical and DXA measures of BMC (Table 2). In the caudal vertebrae, no relationships between DXA and chemical measures were significant. The strongest relationships between DXA and chemical 
Table 2. Relationship between dual-energy x-ray absorptiometry (DXA) and chemical measures of bone mineral content in mature dairy cows.

\begin{tabular}{lcccc}
\hline & $\mathrm{Ca}, \%$ of ash & $\mathrm{P}, \%$ of ash & $\mathrm{Mg}, \%$ of ash & Ash, \% of DM \\
\cline { 2 - 5 } & \multicolumn{4}{c}{ Coefficient of determination $\left(\mathrm{r}^{2}, \%\right)$} \\
DXA estimated bone mineral content, g & $10.4^{*}$ & $8.8^{*}$ & $8.5^{*}$ & 0.1 \\
$\quad$ Metacarpal & 0.5 & 0.3 & 0.3 & 0.9 \\
Caudal vertebra 14 & 0.2 & 0.7 & 0.2 & 2.1 \\
Caudal vertebra 15 & & & \\
DXA estimated bone mineral density, g/cm & & & \\
Metacarpal & $12.6^{*}$ & $10.6^{*}$ & $7.5^{*}$ & 1.2 \\
Caudal vertebra 14 & 0.4 & 0.2 & 0.1 & 0.1 \\
Caudal vertebra 15 & 2.4 & 0.9 & 0.7 & 0.1 \\
\hline
\end{tabular}

*Regression significant at $P<0.05$.

measures observed were in the metacarpal. Calcium and $\mathrm{P}$ content (proportion of ash) accounted for 12.6 and $10.6 \%$ of the variation in BMD estimated by DXA and 10.4 and $8.8 \%$ of the variation in BMC estimated by DXA. In contrast, several other studies report strong relationships between BMC and BMD estimated with DXA and BMC measured chemically. In the vertebrae of sheep (Pouilles et al., 2000) and in pigs (total body ash; Mitchell et al., 1998), DXA measures accounted for $\geq 90 \%$ of the variation in bone ash. In 4 experiments with broilers, Mitchell et al. (1997) observed that DXA BMC accounted for $46 \%$ of the variation in total body ash of broilers. In that study, prediction of ash content was less precise in larger birds.

\section{Site of Measurement and BMC}

Total bone ash was lower in the caudal vertebrae than in the metacarpal (Table 3), whereas Mg content (proportion of ash) was lower in the metacarpal than the caudal vertebrae. Calcium and $\mathrm{P}$ content of the metacarpal and caudal vertebrae were similar. Total ash and Ca content of caudal vertebra 14 and caudal vertebra 15 were similar, but $\mathrm{P}$ content as a proportion of ash was lower in caudal vertebra 14 than in caudal vertebra 15. Imaging estimates of BMC (peak lateral RBAE, peak medial RBAE, and DXA measures of BMC and BMD) all indicated greater mineral content in the metacarpal than in the caudal vertebrae. These means are reported to demonstrate the sensitivity of $R P$ and DXA relative to chemical measures. The biological importance of these data are limited, however, given the poor relationships observed between imaging and chemical measures of BMC.

The likely explanation for lower bone ash in the caudal vertebrae compared with the metacarpal is the composition of bone. Caudal vertebrae are classified as flat bones and are comprised primarily of trabecular bone, whereas the metacarpal is higher in cortical bone. Cortical bone is compact and dense, and it forms the shaft or diaphysis of long bones and the outside surface of bone (Carter and Spengler, 1978). Cortical bone has a

Table 3. Bone mineral content measured in the metacarpal and caudal vertebrae in mature dairy cows.

\begin{tabular}{|c|c|c|c|c|c|c|}
\hline & $\begin{array}{l}\text { Caudal } \\
\text { vertebrae } 14\end{array}$ & $\begin{array}{l}\text { Caudal } \\
\text { vertebrae } 15\end{array}$ & Metacarpal & $\mathrm{SE}$ & \multicolumn{2}{|c|}{$P<$} \\
\hline $\mathrm{Ca}, \%$ of ash & 38.8 & 38.7 & 39.8 & 0.70 & 0.22 & 0.98 \\
\hline $\mathrm{P}, \%$ of ash & 16.7 & 17.8 & 17.5 & 0.33 & 0.56 & 0.03 \\
\hline $\mathrm{Mg}, \%$ of ash & 6.40 & 6.33 & 5.65 & 0.12 & 0.01 & 0.67 \\
\hline Peak lateral RBAE, mm Al & 4.86 & 4.30 & 20.24 & 0.43 & 0.01 & 0.35 \\
\hline $\mathrm{DXA}^{2}$ estimated $\mathrm{BMC}^{3} \mathrm{~g}$ & 1.02 & 0.80 & 43.5 & 1.77 & 0.01 & 0.93 \\
\hline DXA estimated $\mathrm{BMD},{ }^{4} \mathrm{~g} / \mathrm{cm}^{2}$ & 0.34 & 0.37 & 1.27 & 0.05 & 0.01 & 0.74 \\
\hline
\end{tabular}

${ }^{1} \mathrm{RBAE}=$ Radiographic bone aluminum equivalents.

${ }^{2}$ DXA = Dual-energy x-ray absorptiometry.

${ }^{3} \mathrm{BMC}=$ Bone mineral content.

${ }^{4} \mathrm{BMD}=$ Bone mineral density. 
Table 4. Relationship of stage of lactation with bone mineral content in mature dairy cows.

\begin{tabular}{lcccccccc}
\hline & & & & & & \multicolumn{3}{c}{$\mathrm{P}<$} \\
\cline { 5 - 8 } Stage $^{1}$ & 1 & 2 & 3 & 4 & $\mathrm{SE}^{2}$ & Stage & Linear & Quadratic \\
\hline Metacarpal & & & & & & & & \\
Ca, \% of ash & 40.6 & 40.8 & 41.1 & 40.7 & 0.53 & 0.74 & 0.21 & 0.82 \\
P, \% of ash & 17.8 & 18.4 & 17.9 & 18.0 & 0.25 & 0.08 & 0.03 & 0.03 \\
Mg, \% of ash & 5.77 & 5.79 & 5.60 & 5.82 & 0.18 & 0.65 & 0.92 & 0.28 \\
Ash, \% of DM & 66.9 & 67.8 & 67.8 & 68.8 & 1.72 & 0.27 & 0.12 & 0.30 \\
Caudal vertebra 14 & & & & & & & & \\
Ca, \% of ash & 39.9 & 39.8 & 39.9 & 40.3 & 0.27 & 0.34 & 0.39 & 0.45 \\
P, \% of ash & 17.2 & 17.3 & 17.0 & 17.1 & 0.29 & 0.84 & 0.97 & 0.37 \\
Mg, \% of ash & 6.59 & 6.16 & 6.54 & 6.67 & 0.18 & 0.22 & 0.38 & 0.20 \\
Ash, \% of DM & 43.8 & 46.2 & 46.6 & 44.6 & 2.45 & 0.63 & 0.99 & 0.40 \\
Caudal vertebra 15 & & & & & & & & \\
Ca, \% of ash & 38.3 & 39.5 & 38.0 & 37.1 & 3.10 & 0.97 & 0.96 & 0.87 \\
P, \% of ash & 18.2 & 18.0 & 17.3 & 16.6 & 1.68 & 0.76 & 0.89 & 0.56 \\
Mg, \% of ash & 6.37 & 6.04 & 6.15 & 6.07 & 0.56 & 0.95 & 0.74 & 0.93 \\
Ash, \% of DM & 44.7 & 47.3 & 46.2 & 44.8 & 2.16 & 0.82 & 0.53 & 0.80
\end{tabular}

\footnotetext{
${ }^{1}$ Stage of lactation defined by DIM. Stage 1: <90 DIM, Stage 2: 90 to 150 DIM, Stage 3: 151 to 250 DIM, and Stage 4: $>250$ DIM.

${ }^{2}$ Unequal $\mathrm{n}$, largest SEM $(\mathrm{n}=4)$ reported.
}

porosity ranging from 5 to $30 \%$, and it gives long bones their hardness, rigidity, and compressional strength. In contrast, trabecular bone fills the epiphysis of long bones and forms most of the structure of vertebral bones. Trabecular bone has porosity ranging from 30 to $>90 \%$, and it has approximately $20 \times$ more surface area per unit of volume than cortical bone (Currey, 1959).

Because of its porous nature, trabecular bone plays a larger role in metabolic functions, with a more rapid rate of bone turnover than in cortical bone (Albright, 1987). In midlactation ewes, the trabecular bone lost $50 \%$ of its mineral compared with controls killed in early gestation (Benzie et al., 1959). In contrast, only with severe $\mathrm{Ca}$ or $\mathrm{P}$ restriction was significant loss of bone mineral observed in the diaphysis of long bones (Benzie et al., 1955; Benzie et al., 1959). Although subject to more rapid depletion, the trabecular bone of the vertebrae was also repaired more rapidly than the diaphysis of long bone (Benzie et al., 1955; Benzie et al., 1959).

\section{Relationship of Stage of Lactation and Parity with BMC}

Bone mineral and stage of lactation. Total bone mineral and concentration of $\mathrm{Ca}, \mathrm{P}$, and $\mathrm{Mg}$ were unaffected by stage of lactation in caudal vertebrae 14 and 15 (Table 4). In the metacarpal, total bone mineral and composition of $\mathrm{Ca}$ and $\mathrm{Mg}$ were similar in cows of different stages of lactation, but bone $\mathrm{P}$ composition was highest in cows between 90 and 150 DIM (significant quadratic effect).

The lack of a relationship between stage of lactation and total bone mineral contradicts common understandings of bone resorption and formation following parturition and during lactation. The increased bone resorption commonly observed just after parturition (Braithwaite, 1983) or inferred from negative $\mathrm{P}$ balance in early lactation (Knowlton and Herbein, 2002) would suggest reduced $\mathrm{BMC}$ in early lactation. Using ${ }^{32} \mathrm{P}$ infusion, Braithwaite (1983) observed that sheep mobilized bone mineral in early lactation and late pregnancy regardless of dietary $\mathrm{Ca}$ and $\mathrm{P}$, but that in sheep fed diets formulated to meet $\mathrm{Ca}$ and $\mathrm{P}$ requirements, bone stores were replenished in midlactation. Benzie et al. (1959) observed that in ewes fed a diet containing 4 to $5 \mathrm{~g} / \mathrm{d}$ of $\mathrm{P}$ (approximately equivalent to calculated requirements), mineral content of the cervical vertebrae was lower in midlactation than in the dry period, but no measures were obtained in early lactation.

Also, because of its increased porosity, the caudal vertebrae would be expected to be more responsive to changes in stage of lactation. Instead, we observed no changes in mineral content of the caudal vertebrae with stage of lactation.

Bone mineral and parity. In this study, effects of both age and parity on BMC were initially assessed, and similar effects were observed. Because parity accounted for a greater proportion of the variability in BMC than did age, only the effects of parity will be discussed.

Total BMC was unaffected by parity in all bones (Table 5). Increasing parity increased the Ca content of 
Table 5. Relationship of parity with bone mineral content in mature dairy cows.

\begin{tabular}{|c|c|c|c|c|c|c|c|c|}
\hline & \multicolumn{4}{|c|}{ Parity } & \multirow[b]{2}{*}{$\mathrm{SE}$} & \multicolumn{3}{|c|}{$P<$} \\
\hline & 1 & 2 & 3 & 4 & & Parity & Linear & Quadratic \\
\hline \multicolumn{9}{|l|}{ Metacarpal } \\
\hline $\mathrm{Ca}, \%$ of ash & 40.4 & 40.1 & 40.8 & 41.3 & 0.38 & 0.08 & 0.04 & 0.25 \\
\hline $\mathrm{P}, \%$ of ash & 17.6 & 17.9 & 17.6 & 18.1 & 0.18 & 0.10 & 0.13 & 0.40 \\
\hline $\mathrm{Mg}, \%$ of ash & 5.73 & 5.76 & 5.68 & 5.69 & 0.12 & 0.96 & 0.66 & 0.94 \\
\hline Ash, \% of DM & 66.1 & 66.6 & 67.1 & 67.9 & 1.23 & 0.65 & 0.23 & 0.92 \\
\hline \multicolumn{9}{|c|}{ Caudal vertebra 14} \\
\hline $\mathrm{Ca}, \%$ of ash & 39.9 & 40.6 & 39.9 & 39.7 & 0.19 & 0.01 & 0.07 & 0.02 \\
\hline $\mathrm{P}, \%$ of ash & 17.3 & 17.1 & 17.1 & 17.1 & 0.20 & 0.91 & 0.50 & 0.72 \\
\hline $\mathrm{Mg}, \%$ of ash & 6.77 & 6.73 & 6.40 & 6.21 & 0.13 & 0.01 & 0.01 & 0.52 \\
\hline Ash, \% of DM & 46.1 & 47.1 & 44.2 & 45.5 & 1.75 & 0.67 & 0.49 & 0.95 \\
\hline \multicolumn{9}{|c|}{ Caudal vertebra 15} \\
\hline $\mathrm{Ca}, \%$ of ash & 39.4 & 39.4 & 35.2 & 39.3 & 2.22 & 0.42 & 0.62 & 0.29 \\
\hline $\mathrm{P}, \%$ of ash & 18.2 & 18.0 & 15.8 & 17.6 & 1.20 & 0.49 & 0.41 & 0.37 \\
\hline $\mathrm{Mg}, \%$ of ash & 6.64 & 6.47 & 5.58 & 6.10 & 0.40 & 0.25 & 0.12 & 0.33 \\
\hline Ash, \% of DM & 45.5 & 46.2 & 45.5 & 44.9 & 1.55 & 0.92 & 0.68 & 0.64 \\
\hline
\end{tabular}

the metacarpal linearly, with a similar trend observed for metacarpal $\mathrm{P}$ content $(P<0.10)$. Within caudal vertebra 14, a significant effect of parity on Ca content of caudal vertebra 14 was observed, but the effect was quadratic, with a peak observed in parity 2 and the lowest value in parity 4 . The $\mathrm{Mg}$ content of caudal vertebra 14 decreased with parity (linear effect). In the caudal vertebrae, $P$ content was unaffected by parity.

Our results differ from those of other published research, both in the lack of relationship of parity with total bone mineral and in the significant relationships of parity with bone concentrations of specific minerals. El Shorafa et al. (1979) observed no correlation between age and $\mathrm{Ca}$ and $\mathrm{P}$ content in 41 horses between the ages of $1 \mathrm{~d}$ and $33 \mathrm{yr}$. They reported that bone ash content peaked between 4 and 7 yr of age, declining thereafter. Field et al. (1974) observed increased bone ash with age and no change in bone $\mathrm{Ca}$ as a proportion of ash. The comparisons of Field et al. (1974) were among calves, yearlings, and mature cows rather than between mature animals of advancing age. McCalden et al. (1993) reported no relationship between age and either bone ash or bone $\mathrm{Ca}$ in human cadavers ranging in age from 20 to 102 yr. Our study is different from these in that donor animals were neither immature nor elderly.

Results observed in our study differed from results of other studies that indicated striking changes in BMC with stage of lactation (Benzie et al., 1959; Braithwaite, 1983; Knowlton and Herbein, 2002). This is likely due to differences in sample collection. Rather than repeatedly measuring mineral balance in live animals over time as is possible with total collection or isotope infusion studies, we measured BMC directly in samples obtained at slaughter. This sample set was not ideally suited for measuring changes in mineral content with time, as animals could not be measured repeatedly throughout lactation.

One technique that allows repeated, direct measures of BMC is serial biopsy of the rib bone. Little (1972) reported that the technique of serial biopsy of rib bone allowed more sensitive assessment of mineral status compared with one-time sampling. In the only other published research assessing the relationship of stage of lactation and measured bone mineral in dairy cows, Beighle (1999) conducted serial rib biopsy and observed no change in $\mathrm{P}$ content of cortical rib bone throughout lactation. Calcium content of cortical rib bone (as a proportion of total ash) was higher at parturition and at 30 DIM compared with bone sampled 60 and $120 \mathrm{~d}$ postpartum. Cortical bone was thinner at parturition than later in lactation, however, suggesting that concentration of bone mineral may not be an accurate indicator of total bone mineral reserves (Beighle, 1999).

Changes in total bone mass likely overwhelm changes in mineral concentration in determining body mineral reserves. Benzie et al. (1959) weighed individual bones and the total skeleton, obtaining mass measurements in addition to data on mineral concentration. They reported that the total ash weight of individual bones and the total skeleton in sheep changed more dramatically with mineral deficiency and stage of lactation than did bone ash concentration ( $\mathrm{g} / \mathrm{kg}$ of bone). In human cadavers (McCalden et al., 1993), qualitative changes in bone tissue (porosity) changed more with age than did quantitative changes (bone mineral).

\section{CONCLUSIONS}

Estimates of BMC obtained via DXA and RP were not accurate predictors of BMC measured chemically. 
The weaker relationships between estimates of BMC from 2 imaging techniques and actual measures of BMC observed in this study compared with other studies might be due to differences in the experimental units (mature animals vs. growing). The relatively modest changes in BMC observed with changes in parity and stage of lactation in this study may be due to sampling dead cows of different ages and stages of lactation rather than measuring live cows repeatedly. Direct measurement of bone mineral concentration did not account for changes in total bone mass.

\section{ACKNOWLEDGMENTS}

Financial support for this project was provided by the Virginia Agribusiness Council and the John Lee Pratt Foundation. The authors appreciate the assistance and input of Rhonda Hoffman, Louisa Gay, Krystal Hardin, Christina Holtaway, Julie McKinney, Deborah Ross, and Nancy Wilkinson.

\section{REFERENCES}

Adams, J. E. 1997. Single and dual energy x-ray absorptiometry. Eur. Radiol. (Suppl. 2):S20-S31.

Albright, J. A. 1987. Bone: Physical properties. Pages 213-240 in The Scientific Basis of Orthopedics. J. A. Albright and R. A. Brand, ed. Appleton and Lang Publishers, Norwalk, CT.

Asociation of Official Analytical Chemists. 1990. Official Methods of Analysis of AOAC International, 16th ed. AOAC, Washington, DC

Beighle, D. E. 1999. The effects of gestation and lactation on bone calcium, phosphorus and magnesium in dairy cows. J. S. Afr. Vet. Assoc. 70:142-146.

Beiseigel, J. M., and S. M. Nickols-Richardson. 2002. Anthropometrics, bone mineral density, and dietary intake in a group of young adult females. Fam. Consum. Sci. Res. J. 30:404-423.

Benzie, D., A. W. Boyne, A. C. Dalgarno, J. Duckworth, and R. Hill. 1959. The relationship between phosphorus intake and resorption and repair of the skeleton in pregnancy and lactation. J. Agric. Sci. 52:1-12.

Benzie, D., A. W. Boyne, A. C. Dalgarno, J. M. Duckworth, R. Hill, and D. M. Walker. 1955. The effect of different levels of dietary calcium during pregnancy and lactation on individual bones. J. Agric. Sci. 46:425-439.

Braithwaite, G. D. 1983. Calcium and phosphorus requirements of the ewe during pregnancy and lactation 2. Phosphorus. Br. J. Nutr. 50:711-722.

Carter, D. R., and D. M. Spengler. 1978. Mechanical properties and composition of cortical bone. Clin. Orthop. 135:192-217.

Currey, J. D. 1959. Differences in tensile strength of bone of different histological types. J. Anat. 98:87-95.

Dacke, C. G., S. Arckle, D. J. Cook, I. M. Wormstone, S. Jones, M. Zaidi, and Z. A. Bascal. 1993. Medullary bone and avian calcium regulation. J. Exp. Biol. 184:63-68.

Ekman, B., K. G. Linquist, and U. Stein. 1970. Roentgenologic-photometric method for bone mineral determinations. Acta Radiol. Diagn. 10:305-325.

El Shorafa, W. M., J. P. Feaster, and E. A. Ott. 1979. Horse metacarpal bone: Age, ash content, cortical area and failure stress interrelationships. J. Anim. Sci. 49:979-982.

Field, R. A., M. L. Riley, F. C. Mello, M. H. Corbridge, and A. W. Kotula. 1974. Bone composition in cattle, pigs, sheep and poultry. J. Anim. Sci. 39:493-499.
Harris, W. P., and P. Popat. 1954. Determination of the phosphorus content of lipids. J. Am. Oil Chem. Soc. 31:124-127.

Hoffman, R. M., L. A. Lawrence, D. S. Kronfeld, W. L. Cooper, D. J. Sklan, J. J. Dascanio, and P. A. Harris. 1999. Dietary carbohydrates and fat influence radiographic bone mineral content of growing foals. J. Anim. Sci. 77:3330-3338.

Horst, R. L., J. P. Goff, T. A. Reinhardt, and R. D. Buxton. 1997. Strategies for preventing milk fever in dairy cattle. J. Dairy Sci. 80:1269-1280.

Keene, B. E., K. F. Knowlton, J. H. Wilson, M. L. McGilliard, and C. Holtaway. 2004. Bone breaking strength in mature dairy cows. Trans. ASAE.

Knowlton, K. F., and J. H. Herbein. 2002. Phosphorus partitioning during early lactation in dairy cows fed diets varying in phosphorus content. J. Dairy Sci. 85:1227-1236.

Lawrence, L. A. 1986. The use of non-invasive techniques to estimate bone mineral content and bone strength in the horse. Ph.D. Diss., Univ. of Florida, Gainesville.

Little, D. A. 1972. Bone biopsy in cattle and sheep for studies of phosphorus status. Aust. Vet. J. 12:668-670.

Loveridge, N. 1999. Bone: More than a stick. J. Anim. Sci. 77(Suppl. 2):190-196.

Mazess, R. B., H. S. Barden, J. P. Bisek, and J. Hanson. 1990. Dualenergy x-ray absorptiometry for total-body and regional bone mineral and soft-tissue composition. Am. J. Clin. Nutr. 51:1106-1112.

McCalden, R. W., J. A. McGeough, M. B. Barker, and C. M. CourtBrown. 1993. Age-related changes in the tensile properties of cortical bone. The relative importance of changes in porosity, mineralization and microstructure. J. Bone Joint Surg. Am. 75:1193-1205.

Meakim, D. W., E. A. Ott, R. L. Asquith, and J. P. Feaster. 1981. Estimation of mineral content of the equine third metacarpal in radiographic photometry. J. Dairy Sci. 53:1019-1026.

Miles, P. H., N. S. Wilkinson, and L. R. McDowell. 2001. Analysis of Minerals for Animal Nutrition Research. 3rd ed. Dep. Anim. Sci., University of Florida, Gainesville.

Mitchell, A. D., J. M. Conway, and A. M. Scholz. 1996. Incremental changes in total and regional body composition of growing pigs measured by dual-energy X-ray absorptiometry. Growth Dev. Aging 60:95-105.

Mitchell, A. D., R. W. Rosebrough, and J. M. Conway. 1997. Body composition analysis of chickens by dual energy x-ray absorptiometry. Poult. Sci. 76:1746-1752.

Mitchell, A. D., A. M. Scholz, and J. M. Conway. 1998. Body composition analysis of small pigs by dual energy x-ray absorptiometry. J. Anim. Sci. 76:2392-2398.

Mitchell, A. D., A. M. Scholz, and V. G. Pursel. 2001. Total body and regional measurements of bone mineral content and bone mineral density in pigs by dual energy X-ray absorptiometry. J. Anim. Sci. 79:2594-2604.

Morse, D., H. H. Head, C. J. Wilcox, H. H. VanHorn, C. D. Hissem, and J. B. Harris. 1992. Effects of concentration of dietary phosphorus on amount and rate of excretion. J. Dairy Sci. 75:3039-3049.

Omnell, K. 1957. Quantitative roentgenologic studies on changes in mineral content of bone in vivo. Acta Radiol. Suppl. 148:5-83.

Porr, C. A., D. S. Kronfeld, L. A. Lawrence, R. S. Pleasant, and P. A. Harris. 1998. Deconditioning reduces mineral content of the third metacarpal bone in horses. J. Anim. Sci. 76:1875-1879.

Pouilles, J. M., P. Collard, F. Tremollieres, P. Frayssinet, J. J. Railhac, J. P. Cahuz, A. Autefage, and C. Ribot. 2000. Accuracy and precision of in vivo bone mineral measurements in sheep using dual energy X-ray absorptiometry. Calcif. Tissue Int. 66:70-73.

SAS User's Guide, Version 8.0 ed. 1999. SAS Inst., Inc., Cary, NC.

Shupe, J. L., J. E. Butcher, J. W. Call, A. E. Olson, and J. T. Blake. 1988. Clinical signs and bone changes associated with phosphorus deficiency in beef cattle. Am. J. Vet. Res. 49:1629-1636.

Sink, S. E., K. F. Knowlton, and J. H. Herbein. 2000. Economic and environmental implications of overfeeding phosphorus on Virginia dairy farms. J. Anim. Sci. 78(Suppl. 2):4. (Abstr.)

Williams, S. N., L. A. Lawrence, L. R. McDowell, N. S. Wilkinson, P. W. Ferguson, and A. C. Warnick. 1991. Criteria to evaluate bone mineralization in cattle: I. Effect of dietary phosphorus on 
chemical, physical and mechanical properties. J. Anim. Sci. 69:1232-1242.

Williams, S. N., L. R. McDowell, L. A. Lawrence, N. S. Wilkinson, P. W. Ferguson, and A. C. Warnick. 1990. Criteria to evaluate mineralization in cattle: II. Noninvasive techniques. J. Anim. Sci. 69:1243-1254.

Wu, Z., L. D. Satter, A. J. Blohowiak, R. H. Stauffacher, and J. H. Wilson. 2001. Milk production, estimated phosphorus excretion, and bone characteristics of dairy cows fed different amounts of phosphorus for two or three years. J. Dairy Sci. 84:1738-1748.

Wu, Z., L. D. Satter, and R. Sojo. 2000. Milk production, reproductive performance and fecal excretion of phosphorus by dairy cows fed three amounts of phosphorus. J. Dairy Sci. 83:1028-1041.

Yang, R. S., S. S. Wang, H. J. Lin, T. K. Liu, Y. S. Hang, and K. S. Tsai. 1998. Differential effects of bone mineral content and bone area on vertebral strength in a swine model. Calcif. Tissue Int. 63:86-90. 